\title{
Addendum to Immobilization-Enabled Proton-Reduction Catalysis by a Di-iron Hydrogenase Mimic
}

\author{
Jean Sanabria-Chinchilla • Alnald Javier • \\ Danielle Crouthers • Jack H. Baricuatro • \\ Marcetta Y. Darensbourg • Manuel P. Soriaga
}

Published online: 21 February 2014

(C) Springer Science+Business Media New York 2014

It may perhaps be conjectured that the mercapto-free di-iron hydrogenase complex, $\left(\mu\right.$-pdt) $\left[\mathrm{Fe}(\mathrm{CO})_{3}\right]\left[\mathrm{Fe}(\mathrm{CO})_{2}\left(\mathrm{PPh}_{3}\right)\right]$, is inactive towards proton reduction because it is decomposed upon exposure to the Au electrode and that the decomposition products poison the catalysis. If decomposition and catalyst inhibition actually transpired, it would only be because the interaction between the surface and the molecular fragment is much stronger than the bond between that fragment and the constituents within the intact complex. The presence of the chemisorbed residue can thus be established by simple cyclic voltammetry of the $\mathrm{Au}$ electrode in $1.0 \mathrm{M} \mathrm{H}_{2} \mathrm{SO}_{4}$ after immersion in pure acetonitrile and after exposure to the hydrogenase mimic dissolved in acetonitrile. The electrode is rinsed in sulfuric acid solution prior to the voltammetric experiments. The results are shown in Fig. 1. The fact that the two sets of current-potential curves are superimposable provides clear evidence that the mercapto-free complex is neither decomposed nor chemisorbed when exposed to the Au electrode surface.

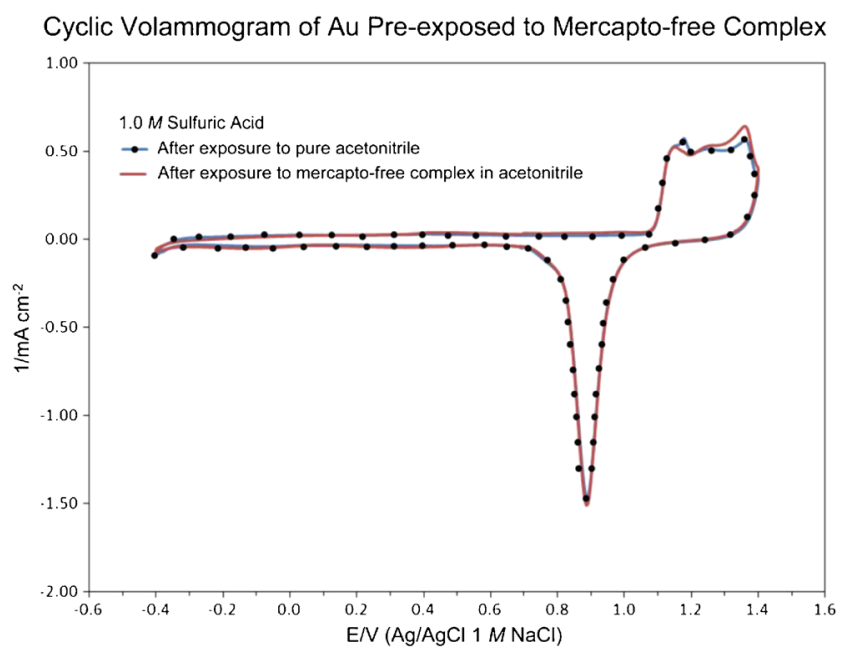

Fig. 1 Cyclic voltammogram in $1.0 \mathrm{M} \mathrm{H}_{2} \mathrm{SO}_{4}$ of a smooth polycrystalline $\mathrm{Au}$ electrode exposed to pure acetonitrile (spittled line) and to acetonitrile that contained $0.5 \mathrm{mM}$ of $(\mu$-pdt $)\left[\mathrm{Fe}(\mathrm{CO})_{3}\right]\left[\mathrm{Fe}(\mathrm{CO})_{2}\left(\mathrm{PPh}_{3}\right)\right]$ (solid line). Potential sweep rate, $10 \mathrm{mV} \mathrm{s}^{-1}$

The online version of the original article can be found http://dx.doi.org/ 10.1007/s12678-013-0157-y.

J. Sanabria-Chinchilla $\cdot$ A. Javier $\cdot$ J. H. Baricuatro · M. P. Soriaga Joint Center for Artificial Photosynthesis, Division of Chemistry and Chemical Engineering, California Institute of Technology, Pasadena, CA 91125, USA

A. Javier $\cdot$ D. Crouthers $\cdot$ M. Y. Darensbourg $\cdot$ M. P. Soriaga $(\square)$

Department of Chemistry, Texas A\&M University, College Station,

TX 77843, USA

e-mail: soriaga@mail.chem.tamu.edu 